\title{
Bridging the gap between cognitive neuroscience and education: Psychophysiological and behavioral data collection in authentic contexts
}

https://doi.org/10.24046/neuroed.20120101.5

\author{
Julien MERCIER ${ }^{1}$ * , Pierre-Majorique LÉGER ${ }^{2}$, Caroline GIRARD ${ }^{1}$, and \\ Jan-Sébastien DION ${ }^{1}$
}

1 Université du Québec à Montréal

2 HEC Montréal

*Email: mercier.julien@uqam.ca

\begin{abstract}
Psychophysiological correlates of learning and performance are currently viewed as an important source of information for the improvement of many spheres of human activity, including the field of education. Studies in neuroeducation are likely to benefit from the concomitant analysis of different levels in the cognitive architecture (psychophysiological, cognitive, and social cognitive). The case study reported herein is concerned with the psychophysiological and cognitive levels. The objective is to test a methodology permitting, on the one hand, to relate data from EEG and data from a thinkaloud procedure collected simultaneously during the performance of a problemsolving task in a semantically-complex domain and, on the other hand, to test hypotheses regarding functional relationships between those levels. During a two-hour experiment, a single participant planned remedial reading activities on the basis of a description of a student having reading difficulties. The procedure for data preparation is presented. Then, as an illustration of the methodology, hypotheses involving both levels are tested. Results show that the methodology can establish correlational relations between targeted levels in terms of cooccurrence of cognitive and psychophysiological states. They also show that an EEG trace transformed into 1-second intervals characterizing brain states is not sufficiently fine-grained to test causal relationships based on the temporality of the data. This study stresses the need to explore the phenomenon of rapidlytransitioning psychophysiological microstates in the context of neuroeducational research.
\end{abstract}




\section{Introduction}

Psychophysiological correlates of learning and performance are currently viewed as an important source of information for the improvement of many spheres of human activity, including the field of education (Geake, 2011). Recent advances both in equipment and methodology such as dense-array EEG nets, source localization algorithms, and built-in spectral analysis capability, have opened new fields of research exploring how the brain enables cognition in various domains (Ansari, Coch, \& De Smedt, 2011). This progress is further fueled by the efforts of many cognitive neuroscientists to overcome difficulties inherent to the conduct of experiments with higher ecological validity (Grabner \& Ansari, 2010). To this end, calls for collaboration between educational researchers and cognitive neuroscientists as well as needs for training researchers in both disciplines are frequently being formulated (see for example Ansari, Coch, \& De Smedt, 2011). In our opinion, coupling psychophysiological data with behavioral data may be one of the most promising endeavors with respect to the advancement of research in the learning sciences in this context. Indeed, the study of constructs prevalent in current research such as self-regulated learning, engagement, cognitive load, increasingly conceived of as dynamic series of events, can greatly benefit from online, unobtrusive, and fine-grained measures during the course of a learning situation. Contingency, the dynamic adaptation of agents in a learning situation in the form of scaffolding, (Wood \& Wood, 1999), rests on a moment-by-moment characterization of the state of a learner, or of a group of learners. In particular, the development of intelligent tutoring systems (ITS), hinging on online models of the learners which inform the ITS regarding its next moves in a learning interaction, inherently depends on better and more complete ways of characterizing the cognitive and affective states of the learner during a learning task, as ongoing research in this direction testifies (Azevedo, Moos, Johnson, Chauncey, 2010; Chi, VanLehn, Litman, \& Jordan, 2011; D'Mello \& Graesser, 2012). Recent research on tutoring has shown that the frequency of this characterization of the state of the learner is particularly important (Van Lehn, 2011). Psychophysiological measures represent the extreme limit of this desired high frequency, well beyond speech and other behavioral traces of cognition, as further discussed in section 1.1 .

However, most of the research necessary to take advantage of psychophysiological measures in order to help people learn and develop remains to be done. Key to this endeavor is the integration of psychophysiological measures within the best research currently conducted in the field education. One aspect of such research rests on the assumption 
that learning is best understood in terms of complex "trajectories" (Lajoie, 2003). These trajectories are series of events that bring cumulative changes in knowledge and skills. They occur over radically different timescales and can be fully understood only in terms of continuities, discontinuities, iterations, false starts, etc. These trajectories rest on genetic and developmental foundations, but are dramatically influenced by human agency, both internal and external to the learner. Some crucial events constituting those trajectories are observable through actions and speech (so-called behavioral data), whereas others occur secretly within the confines of the brain and cannot be subjected to conscious examination and verbalization (so-called psychophysiological data). One the one hand, research in education relies exclusively on behavioral data. On the other hand, psychophysiological data are collected and interpreted in the context of tasks very remote from situations considered ecologically-valid in educational research.

To this end, one pressing need is to obtain these psychophysiological measures in authentic contexts of human activity, and in conjunction with behavioral data typical of the contemporary study of cognition. Therefore, the objectives underlying the current study are: (1) to test a methodology which relates EEG data with data from a think-aloud protocol, and (2) to examine functional relations between psychophysiological and cognitive levels in the context of the performance of a complex cognitive task by a domain expert.

The following sections describe a view of human cognition from the perspective of cognitive science, insisting on process-oriented methodologies and constructs. Then, the psychophysiological and behavioral constructs under study are presented.

\subsection{A multi-level architecture of human cognition}

Human cognition is widely understood as an information-processing system constituted of many superimposed levels (Anderson, 2002; Newell, 1990; Sun, 2006). Those levels are commonly distinguished on the basis of their implementation, that is, qualitative differences in the system by which the information is manipulated (see Table 1). 
Table 1. Time scales in cognitive modeling: a bridge between fast-occurring events and their effects on learning.

\begin{tabular}{|c|c|c|c|c|}
\hline $\begin{array}{l}\text { Aspect of } \\
\text { learning }\end{array}$ & $\begin{array}{l}\text { Time unit required for } \\
\text { change to occur at } \\
\text { that level }\end{array}$ & Description & Definition (Newell, 1990) & Data source \\
\hline \multicolumn{5}{|c|}{ Inter-individual cognitive processes } \\
\hline \multirow[t]{3}{*}{ Social } & Months & & & Conversation \\
\hline & Weeks & & & Conversation \\
\hline & Days & & & Conversation \\
\hline \multicolumn{5}{|c|}{ Intra-individual cognitive processes } \\
\hline \multirow[t]{3}{*}{ Rational } & Hours & Task & \multirow{3}{*}{$\begin{array}{l}\text { The tasks representing } \\
\text { these three levels are } \\
\text { composed according to the } \\
\text { structure of a cognitive task, } \\
\text { and are therefore bound to } \\
\text { the context. }\end{array}$} & Speech \\
\hline & 10 minutes & Task & & Speech \\
\hline & Minutes & Task & & Speech \\
\hline \multirow[t]{3}{*}{ Cognitive } & 10 seconds & Unit Task & $\begin{array}{l}\text { Constitute the composite } \\
\text { operators. }\end{array}$ & Speech \\
\hline & Seconds & Operations & $\begin{array}{l}\text { Constitute the operators on } \\
\text { the basis of deliberate acts } \\
\text { to being the search in the } \\
\text { problem space. }\end{array}$ & Speech \\
\hline & Tenths of a second & Deliberate act & $\begin{array}{l}\text { Use available knowledge to } \\
\text { choose an operation. This } \\
\text { process is automatic and } \\
\text { unconscious. }\end{array}$ & Eye-tracking \\
\hline \multicolumn{5}{|c|}{ Intra-individual psychophysiological processes } \\
\hline \multirow[t]{3}{*}{ Biological } & $\begin{array}{l}\text { Hundredths of a } \\
\text { second }\end{array}$ & Neural circuit & Microstates & $\begin{array}{l}\text { Electro- } \\
\text { encephalography }\end{array}$ \\
\hline & $\begin{array}{l}\text { Thousandths of a } \\
\text { second }\end{array}$ & Neuron & & \\
\hline & $\begin{array}{l}\text { Ten-thousandths of a } \\
\text { second }\end{array}$ & Organelle & & \\
\hline
\end{tabular}

Note. Shaded time scales represent cognitive events occurring faster than speech.

For the purpose of this study, the architecture is represented in terms of three levels corresponding to (intra-individual) psychophysiological functioning, intra-individual cognitive functioning, and inter-individual cognitive functioning. Within this framework, cognitive functioning can be examined from the perspective of within-level processes associated with a specific level or alternatively from the perspective of between-level processes. Indeed, each 
level has its own rules, principles and constraints, but a level also functions in response to bidirectional relationships along with the adjacent levels. In this light, it can be said that bottom-up influences include a time dependency principle, in which higher-level, more complex processes are slower. Conversely, top-down influences include an agency principle, according to which social and cognitive demands drive respectively the intra-individual cognitive and psychophysiological processes. This framework formalizes how brains, individuals, and groups (including dyads) operate, and can be used to make predictions regarding how events pertaining to one entity may affect other events at the same or different level(s). This is crucial in studying how people develop in terms of complex trajectories of events and states, and this is why research programs in emerging neuroeducation can greatly benefit from the study of inter-level influences in educationally-significant contexts of learning and performance.

\subsection{Process-oriented methodologies}

Online data collection procedures (leaving aside retrospective methods) include conversation data, think-aloud protocols, and psychophysiological measures (such as EEG, fMRI, and skin conductance). These methodologies can provide data associated with all levels of the architecture pertaining to human cognition that are of interest for the learning sciences. The problem is that speech is per se a complex cognitive activity involving many brain regions, and as such, it introduces substantial noise in the signal of brainimaging techniques. Moreover, the electrical activity associated to the muscles responsible for facial movements, including those induced by speech, is also reflected in methodologies based on electric fields, such as EEG. Given the interest of coupling behavioral data with psychophysiological data for the advancement of research in the field, and given the pervasiveness of conversation and movement in natural learning and performance settings, there is a pressing need for methodological tactics to obtain valid data in authentic contexts of learning and performance. In this vein, studies have recently begun to show that EEG data can be collected and interpreted under realistic performance settings (Stevens et al., 2011). Synchronicities were detected on the basis of spectral analysis. However, these results do not inform about the extent of the possibility of adequately interpreting mental states using constructs of educational significance in contexts of educational significance, and doubts continue to pervade recent literature despite growing enthusiasm (Lee \& Ng, 2011).

The analytical strategies associated with process-oriented data include the prevalence of given states (in terms of frequency and/or duration). 
Prevalence can be targeted descriptively (in terms of relative occurrence of particular states) or from a correlational view. This correlational view includes relationships between the prevalence of given states and relationships of the prevalence of given states with outcome measures. Alternatively, a sequential approach focuses on how events unfold over time. To study this sequencing of events, Markovian models (see Gottman \& Roy, 1990) can be applied when events are formulated in terms of a finite space of discrete states, whereas fractal scaling (Moscoso del Prado Martin, 2011, 2011) applies to patterns expressed through continuous variables.

\subsection{Cognitive load, engagement and alertness during pedagogical reasoning as the context of the study}

\subsubsection{Pedagogical reasoning}

Pedagogical reasoning characterizes, from an information-processing point of view, how a teacher attends to and builds a representation of a teaching situation, how hypotheses related to students' current state are derived and tested, and how potentially contingent instruction is elaborated. This process occurs whenever the teacher needs information to the following questions: What is the information available regarding a student's learning and what is the meaning of this information? What are the difficulties of the student? What can I do to help this student learn? These questions are usually related to a particular learning domain, such as mathematics or reading, but can also target domain-generic learning skills, such as academic self-regulation. Pedagogical reasoning is a complex cognitive task in the sense that it is constituted of very high level mental processes that have to be based on vast amounts of domain knowledge to be successfully performed (Mercier, Girard, Brodeur \& Laplante, 2010). Studies have shown that this cognitive activity varies in both form and content, according to expertise. This task is chosen as the context of this study for a number of reasons. Firstly, pedagogical reasoning represents complex problem solving that matches the complexity of cognitive functioning of individuals in a learning situation, both the teacher and the student(s). This complexity is crucial in attaining the goals of this study. Secondly, pedagogical reasoning is usually a solitary process, yet important and authentic in the sense that pedagogical reasoning represents a crucial and frequent activity in the daily practice of a teacher. This task appeared to be a sound choice given the availability of only one EEG net in our lab at the time of data collection and the interest in further studying pedagogical reasoning. Thirdly, given the many challenges inherent to the psychophysiological level in the present pilot study, our well-established work regarding the conceptualization and operationalization of pedagogical 
reasoning provides a firm anchor at the behavioral level. Finally, our previous work indicates that a meaningful pedagogical reasoning episode can be captured in a two-hour experiment, which corresponds well to the timeframe of our envisioned use of EEG in data collection. Figure 1 presents the main constituents of pedagogical reasoning, based on the conceptualization of Mercier, Girard, Brodeur, \& Laplante (2010).
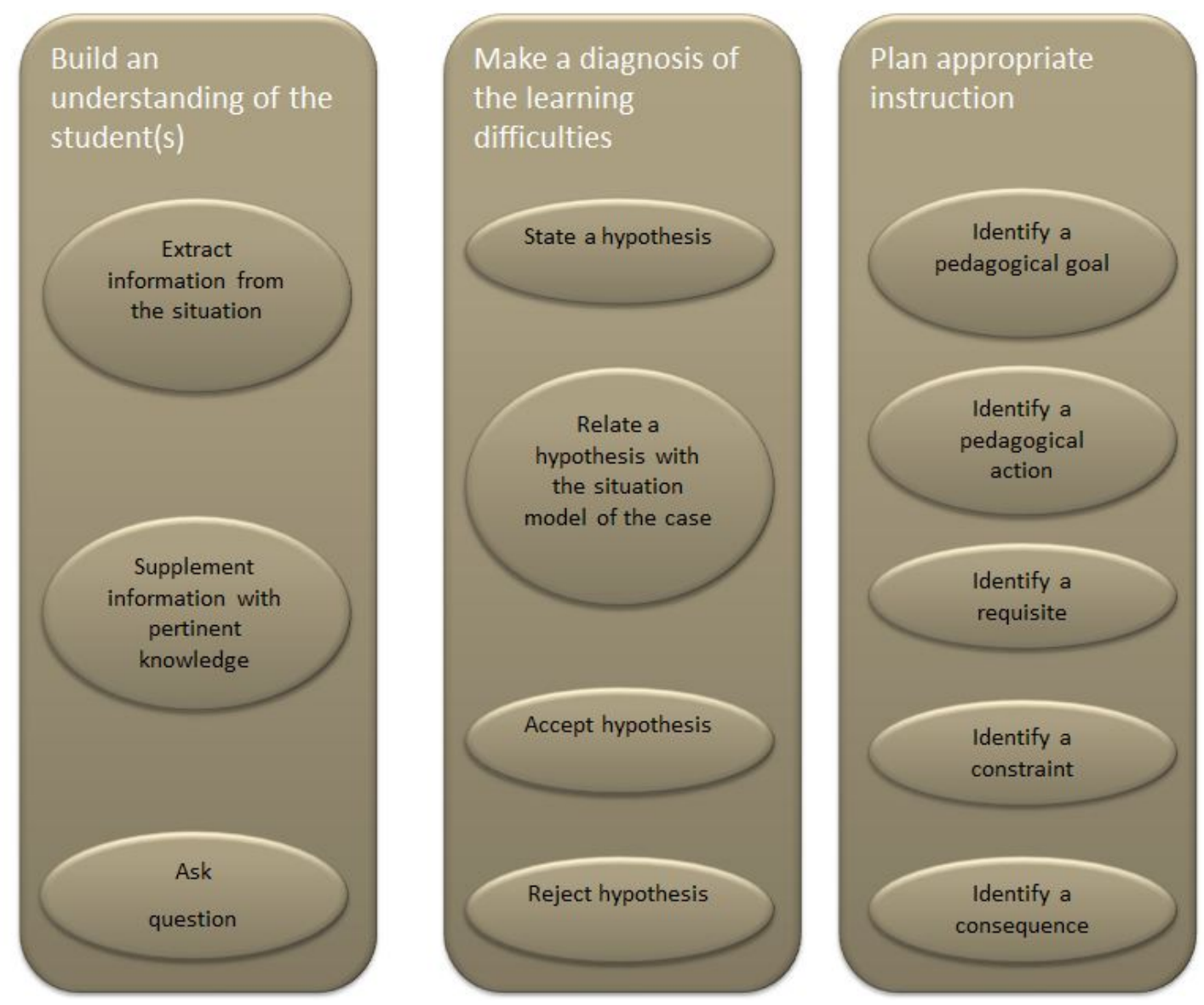

Figure 1. An information-processing model of pedagogical reasoning.

Pedagogical reasoning is articulated around three high-level cognitive processes: comprehension, reasoning and planning. Comprehension refers to building a mental model of the situation, with a particular emphasis on the distinction between information provided in the situation and information eventually extracted from the domain knowledge of the teacher. Reasoning specifies the main operations needed to elaborate and test hypotheses. In the context of pedagogical reasoning, the hypotheses are related to the condition 
or difficulties of the learner(s). Finally, planning refers to the operations leading to an action plan representing the pedagogical approach, settings, activities, etc., that are likely to help students learn and overcome their hypothesized difficulties. Studies of pedagogical reasoning in laboratory indicated that comprehension and reasoning are typically enacted recursively and followed by a relatively stand-alone planning episode. Studies in authentic contexts have shown that these processes are often interrupted and intertwined between students. Although a certain coherence of the process is observed over weeks, its efficiency in terms of task regulation is sub-optimal at this time scale (Mercier, 2012b).

Together, these three processes constitute the task performance aspect of pedagogical reasoning. They are thought to interact together according to task demands through problem solving. For the purpose of this study, problem solving is reduced to an action-regulation framework (Tschan, 2002) emphasizing the preparation, execution, and evaluation of performance. While the execution of the task comprises the categories associated with comprehension, reasoning and planning, preparation corresponds to goal setting and action planning. Evaluation includes the assessment of the outcomes of the performance (including sub-tasks), and corrections when needed.

\subsubsection{Constructs measured through a psychophysiological method}

The constructs under study are those measured by the equipment used. Probabilities for drowsiness, distraction, low and high engagement, probability of high workload based on forward and backward digit span (FBDS), backward digit span (BDS), and average of FBDS and BDS are estimated for each one-second interval on the basis of 256 measures at each electrode collected during that period (i.e. at $256 \mathrm{hz}$ ). Task engagement was defined as a subjective experience which incorporates "challenge, aesthetic and sensory appeal, feedback, novelty, interactivity, perceived control and time, awareness, motivation, interest, and affect" (O'Brien \& Toms, 2008, p. 949). Task engagement includes an "effortful striving directed toward task goals", which increased during a demanding cognitive task and declined when participants had to perform a sustained and monotonous vigilance task (Matthews et al., 2002, p. 335). It is also associated with the amount of effort, which has to be engaged in a task. Workload is defined as the investment of cognitive resources induced by task demands (Wickens \& Hollands, 1999). Distraction can be understood as a shift of attention towards off-task elements, whereas drowsiness is associated with a lowered vigilance. 


\subsubsection{Engagement, workload, distraction and drowsiness during pedagogical reasoning}

The theory linking psychophysiological constructs and the performance of a semantically-complex task appears to be rather thin, making hypotheses highly speculative. Nevertheless, correlational relationships are postulated between psychophysiological constructs and (1) the type of cognitive activity (action regulation or task execution) and (2) the task component (comprehension, reasoning, or planning).

Engagement is expected to be higher during action regulation since action regulation is explicitly related to the processing of task goals. In contrast, workload is postulated to be equal. Cognitive load theory (Sweller, 1988) indicates that workload associated with action regulation is minimal when the individual has appropriate schemas of the task in memory which are matched to the task demands and activated (Kalyuga, 2009); this is likely to be the case with a domain expert. Finally, distraction and drowsiness are expected to be lower during action regulation since these states can be thought of as indicators of sub-optimal regulation, in the sense that distraction and drowsiness inherently prevent transitions from task performance to action regulation.

In the case of task components, engagement and workload are hypothesized to be higher for comprehension and reasoning. On the one hand, task engagement can be related to the curiosity in discovering a novel case (Mercier, Girard, Brodeur, \& Laplante, 2010). On the other hand, high workload can be induced by the vast amount of information contained in the description of the case (Patel, Arocha, \& Zhang, 2005). Conversely, engagement and workload are expected to be lower for planning as this is a fairly routine activity for an expert when appropriate schemas are already present in memory (Mercier, Girard, Brodeur, \& Laplante, 2010). An expert possesses a vast amount of compiled action plans, and it could be expected that matching an action plan with the student's difficulties is achieved merely by means of a brief search within pertinent knowledge (Patel, Arocha, \& Zhang, 2005). Moreover, expressing the selected action plan can be characterized as monotonous. Finally, the sub-optimal performance of the task for which distraction and drowsiness are indicators, is expected to occur randomly during the task, as a result of factors not considered in this study, such as time on task, time of the day, and other events which are part of the natural setting of the experiment. 


\subsubsection{Research questions and hypotheses}

The research questions investigate the relationships between cognitive states pertaining to two different levels of the cognitive architecture, as measured psychophysiologically and behaviorally. The two questions address different hierarchical levels in the cognitive model of pedagogical reasoning, while involving the same four psychophysiological constructs: (1) is the type of cognitive activity (action regulation or task execution) associated with the probabilities of being in a state of high engagement and low engagement, high workload, distraction and drowsiness? (2) is the task component (comprehension, reasoning, or planning) associated with the probabilities of being in a state of high engagement and low engagement, high workload, distraction and drowsiness? The following hypotheses are derived for each question:

Cognitive activity (action regulation or task execution)

$\mathrm{H} 1$ : Engagement is higher during action regulation

$\mathrm{H} 2$ : Workload is equal among types of cognitive activity

H3: Distraction is lower during action regulation

$\mathrm{H} 4$ : Drowsiness is lower during action regulation

Task components (comprehension, reasoning, or planning)

H5: Engagement is higher for comprehension and reasoning

H6: Workload is higher for comprehension and reasoning

$\mathrm{H} 7$ : Distraction is equal among task components

$\mathrm{H} 8$ : Drowsiness is equal among task components

\section{Methodology}

\subsection{Participant}

The participant in this case study is a right-handed expert teacher in remedial reading instruction. She has 20 years of teaching experience with at-risk students, either in one-on-one tutoring or small-group contexts. She holds a practice-oriented graduate degree specialized in remedial reading instruction. She was identified as an expert by a colleague of the first author, with whom she had worked for many years. The participant received a small monetary compensation for her participation, as well as a debriefing regarding the results of the study a few months later. 


\subsection{Task and data collection procedure}

The participant was asked to plan remedial reading instruction for a student on the basis of an authentic case. To this end, she was provided with a 12page description of a real student containing a phonological transcription of an excerpt from the student's oral reading, the questions and answers from a comprehension test, as well as the transcription of a metacognitive interview. She used a computer to display the case contained in a PDF file, and to write down her lesson plans using a word-processor. She was also provided with a pen and paper. The EEG system used, ABM's B-Alert $₫$, has been described by Stevens et al. (2011) as follows:

The ABM, B-Alert ${ }^{\circledR}$ system contains an easily-applied wireless EEG system that includes intelligent software designed to identify and eliminate multiple sources of biological and environmental contamination, and allow real-time classification of cognitive state changes even in challenging environments. The 9-channel wireless headset includes sensor site locations: F3, F4, C3, C4, P3, P4, Fz, $\mathrm{Cz}, \mathrm{POz}$ in a monopolar configuration referenced to linked mastoids. ABM B-Alert $₫$ software acquires the data and quantifies alertness, engagement and mental workload in real-time using linear and quadratic discriminant function analyses with modelselected Power Spectral Density (PSD) variables in each of the 1$\mathrm{Hz}$ bins from $1-40 \mathrm{~Hz}$, ratios of power bins, event-related power and/or wavelet transform calculations (p. 7).

The EEG net was installed on the participant's scalp and repositioned until the impedance of each electrode was adequate. Then, the baseline data for calibration of the spectral analysis software was acquired, using the 15minute set of tasks included in the EEG system. The neuropsychological tasks were used to build the system's algorithm using an initial population of 150 healthy individuals, and subsequently used to adapt the classification algorithm to individual differences. The four tasks include the following: the Osler maintenance of wakefulness task, the eyes closed passive vigilance task, the eyes open passive vigilance task, and a 3-choice active vigilance task. These are used to define the four variables derived from the EEG signal, that is, the classes of drowsiness onset, distraction/relaxed wakefulness, low engagement, and high engagement, respectively. This method provides a reliable algorithm that enables the cognitive state models to be applied to complex tasks and situations. For example, these methods have proven valid during driving simulation, simple and complex cognitive tasks, as well as in military, industrial and educational simulation environments (Berka et al., 2004, 2007; Stevens et al., 2011). New contexts of application are actively being investigated. Finally, it has been shown that 
the B-Alert $\AA$ workload "indexes are related to cognitive effort associated with task difficulty and not to the number of sensory inputs or the amount of motor output required for the performance" (Berka et al., 2004, p. 166).

Afterwards, the participant was briefed regarding the task, and was asked to think out loud, that is, to verbalize anything that comes to mind during the performance of the task. A trained research assistant was present at all time, in a room where the participant could not see him, to monitor the EEG data acquisition and to remind her to talk aloud each time nothing was said for five seconds.

\subsection{Data preparation and plan of analysis}

The EEG data processing begins with the decontaminated EEG (for fast and slow eye blinks, data points contaminated with electromyography (EMG, i.e. facial movements, amplifier saturation, or excursions due to movement artifacts) using a combination of signal-transformation operations including high-pass and low-pass filters, cross-correlation analysis and Fast-Fourier transform (Berka et al., 2004). In its form ready for analysis, the data consist of a file containing second-by-second calculations of the probabilities of being in a state of high engagement, of low engagement, high workload, distraction, and drowsiness (Berka et al., 2004). These time-stamped data were then synchronized with the recording of the speech data.

The think-aloud was transcribed verbatim, and then coded manually using the categories of the pedagogical-reasoning model. The operational definitions, presented in Table 2, were elaborated and refined over three previous studies aiming at validating the model, totaling the coding of more than 50 protocols (Mercier, 2010). 
Table 2. Constituent activities of pedagogical reasoning.

\begin{tabular}{|c|c|}
\hline Category & Definition \\
\hline & Problem-solving \\
\hline Plan goal & Plan the goal to be achieved by this pedagogical reasoning procedure \\
\hline $\begin{array}{l}\text { Plan problem-solving } \\
\text { action }\end{array}$ & Plan the pedagogical reasoning action to be carried out \\
\hline Interpret state & Interpret the current problem state in pedagogical reasoning \\
\hline Test conditions & Test critical conditions for applying a procedure in pedagogical reasoning \\
\hline Evaluate & $\begin{array}{l}\text { Evaluate the result obtained from applying the pedagogical reasoning } \\
\text { procedure }\end{array}$ \\
\hline \multirow[t]{2}{*}{ Correct } & Correct an error or provide a missing component of the solution \\
\hline & Comprehension \\
\hline Comprehend situation & Derive meaning of the situation \\
\hline $\begin{array}{l}\text { Supplement situation } \\
\text { with prior knowledge }\end{array}$ & $\begin{array}{l}\text { Provide information not included in the information available from the } \\
\text { situation }\end{array}$ \\
\hline \multirow[t]{2}{*}{ Ask question } & Diagnose a need for additional information \\
\hline & Diagnosis \\
\hline $\begin{array}{l}\text { Elaborate a } \\
\text { hypothesis }\end{array}$ & Make inferences to identify the problem in the case \\
\hline Organize hypotheses & $\begin{array}{l}\text { In the presence of multiple hypotheses, organize them in terms of } \\
\text { plausibility }\end{array}$ \\
\hline Accept hypothesis & Determine that a hypothesis is supported by the data \\
\hline \multirow[t]{2}{*}{ Reject hypothesis } & Determine that a hypothesis is not supported by the data \\
\hline & Planning \\
\hline Identify goal & Plan the goal to be achieved by implementing the pedagogical intervention \\
\hline Organize goals & In the presence of multiple goals, organize goals hierarchically \\
\hline $\begin{array}{l}\text { Identify pedagogical } \\
\text { action }\end{array}$ & Identify an action contributing to the attainment of the pedagogical goal \\
\hline Identify prerequisite & Identify a condition that must be met before enacting an action \\
\hline Identify corequisite & Identify a condition that must be met during the enactment of an action \\
\hline Identify postrequisite & Identify a condition that must be met to end an action \\
\hline $\begin{array}{l}\text { Identify consequence } \\
\text { and effect }\end{array}$ & Identify the result of the enactment of an action \\
\hline
\end{tabular}


Finally, the coding of the verbatim was associated with the psychophysiological data, on the basis of the system-generated one-second intervals. For each second of the psychophysiological data, the corresponding behavioral activity was entered. In the case of a second during which the behavioral activity transitioned, the activity representing at least $75 \%$ of that interval was specified. Otherwise, no activity was associated.

Multivariate and univariate analysis of variance (MANOVA and ANOVA) were used to test the relationships between the psychophysiological and behavioral levels. For each question, four tests were conducted corresponding to all four psychophysiological constructs. The first series of tests, related to the first question included the type of cognitive activity as the dependent variable (two levels: action regulation or execution) whereas the series of tests concerning the second question involved task components as the dependent variable (three levels: comprehension, reasoning and planning). Distractedness and drowsiness were represented by only one dependent variable each, dictating the use of ANOVA. Workload and engagement were measured by two and three variables respectively, so MANOVAs were performed in those cases. Post-hoc contrasts between the three levels of the dependent variable of question 2 were conducted when a significant relationship was found.

\section{Results}

The psychophysiological data consists of 5035 seconds (about 1 hour and 24 minutes), showing the participant's on-task performance, and excluding the calibration episode, briefing and debriefing. Of these 5035 seconds, 4733 $(94 \%)$ were interpretable by the algorithm and the probability of being in one of the four cognitive states was established. The behavioral level, superimposed on the psychophysiological level, led to the characterization of 3056 seconds, that is, $60.7 \%$ of the 5035 seconds. The results associated with each of the two research questions are discussed next.

\subsection{Type of cognitive activities}

The type of cognitive activity (action regulation or task execution) is not associated with different probabilities of high cognitive load, distraction, or drowsiness. However, the type of cognitive activity is related to different probabilities of being in a state of high or low engagement $\left(F_{2.1455}=5.74\right.$, $p<0.01$ eta $\left.^{2}=0.008\right)$. The relationship is observed for the probability of high engagement $\left(F_{2.1457}=11.47, p<0.01\right.$, eta $\left.{ }^{2}=0.008\right)$ and low 
engagement $\left(F_{2.1457}=8.06, p<0.01\right.$, eta $\left.{ }^{2}=0.006\right)$. The state of high engagement is significantly more probable during action regulation. Conversely, the state of low engagement is significantly less probable during action regulation. The descriptive statistics are presented in Table 3.

Table 3. Descriptive statistics by type of cognitive activity

\begin{tabular}{|c|c|c|c|c|c|c|}
\hline \multirow[t]{2}{*}{ Variables } & \multicolumn{3}{|c|}{ Action regulation } & \multicolumn{3}{|c|}{ Task execution } \\
\hline & $\mathrm{n}$ & M & S.D. & $\mathrm{n}$ & M & S.D. \\
\hline & \multicolumn{6}{|c|}{ High workload } \\
\hline $\begin{array}{l}\text { FBDS } \\
\text { Workload }\end{array}$ & 534 & .65 & 19 & 1753 & .67 & .21 \\
\hline BDS Workload & 534 & .55 & .18 & 1753 & .56 & .19 \\
\hline \multirow[t]{2}{*}{$\begin{array}{l}\text { Average } \\
\text { Workload }\end{array}$} & 534 & .60 & 17 & 1753 & .61 & .19 \\
\hline & \multicolumn{6}{|c|}{ Engagement } \\
\hline $\begin{array}{l}\text { Low } \\
\text { Engagement }\end{array}$ & 417 & .64 & .39 & 1041 & .70 & .36 \\
\hline \multirow{2}{*}{$\begin{array}{l}\text { High } \\
\text { Engagement }\end{array}$} & 417 & .28 & .36 & 1041 & 21 & .32 \\
\hline & \multicolumn{6}{|c|}{ Distraction } \\
\hline \multirow[t]{2}{*}{ Distraction } & 645 & .09 & .23 & 2755 & .08 & .23 \\
\hline & \multicolumn{6}{|c|}{ Drowsiness } \\
\hline Drowsiness & 569 & .00 & .04 & 1702 & .00 & .02 \\
\hline
\end{tabular}

\subsection{Task components}

The three main components of the pedagogical-reasoning task are not associated with the probability of being distracted or drowsy. However, comprehension, reasoning and planning are related to significantly different probabilities of high cognitive load $\left(F_{2.1646}=91.04, p<0.001\right.$, eta $\left.{ }^{2}=0.1\right)$. Specifically, a relationship of similar magnitude is found with all three variables (FBDS $\left(F_{2.1649}=90.87, p<0.001\right.$, eta $\left.^{2}=0.1\right)$; $B D S\left(F_{2.1649}=59.77\right.$, $\mathrm{p}<0.001$, eta $\left.{ }^{2}=0.07\right)$ and Average Workload $\left(F_{2.1649}=81.93, p<0.001\right.$, eta $^{2}$ $=0.09$ ). The contrasts indicate that planning is different from the other task components and is associated with a lower probability of high cognitive load. 
Table 4. Descriptive statistics by task components.

\begin{tabular}{|c|c|c|c|c|c|c|c|c|c|}
\hline \multirow[t]{2}{*}{ Variables } & \multicolumn{3}{|c|}{ Comprehension } & \multicolumn{3}{|c|}{ Reasoning } & \multicolumn{3}{|c|}{ Planning } \\
\hline & $\mathrm{n}$ & $M$ & S.D. & $\mathrm{n}$ & $M$ & S.D. & $\mathrm{n}$ & $M$ & S.D. \\
\hline & \multicolumn{9}{|c|}{ High workload } \\
\hline $\begin{array}{l}\text { FBDS } \\
\text { Workload }\end{array}$ & 640 & .72 & .19 & 508 & .71 & .19 & 501 & .58 & .21 \\
\hline $\begin{array}{l}\text { BDS } \\
\text { Workload }\end{array}$ & 640 & .60 & .18 & 508 & .59 & .18 & 501 & .49 & .18 \\
\hline \multirow[t]{2}{*}{$\begin{array}{l}\text { Average } \\
\text { Workload }\end{array}$} & 640 & .66 & .18 & 508 & .64 & .18 & 501 & .53 & .19 \\
\hline & \multicolumn{9}{|c|}{ Engagement } \\
\hline $\begin{array}{l}\text { Low } \\
\text { Engagement }\end{array}$ & 276 & .70 & .36 & 225 & .84 & .29 & 466 & .64 & .37 \\
\hline \multirow[t]{2}{*}{$\begin{array}{l}\text { High } \\
\text { Engagement }\end{array}$} & 276 & .20 & .32 & 225 & .10 & .24 & 466 & .27 & .35 \\
\hline & \multicolumn{9}{|c|}{ Distraction } \\
\hline \multirow[t]{2}{*}{ Distraction } & 822 & .10 & .26 & 589 & .07 & .21 & 577 & .08 & .21 \\
\hline & \multicolumn{9}{|c|}{ Drowsiness } \\
\hline Drowsiness & 589 & .00 & .00 & 471 & .00 & .03 & 535 & .00 & .02 \\
\hline
\end{tabular}

Similarly, those cognitive processes are associated with the probability of being highly or poorly engaged when the task is being performed $\left(\mathrm{F}_{2.963}=\right.$ 25.82, $p<0.001$, eta ${ }^{2}=0.05$ ). Again, similar effect sizes are found for the two variables involved in low engagement $\left(F_{2.977}=24.36, p<0.001\right.$, eta $\left.^{2}=0.05\right)$ and high engagement $\left(F_{2.977}=21.78, p<0.001\right.$, eta $\left.{ }^{2}=0.04\right)$. Contrasts indicate that reasoning is more strongly associated with low engagement and less with high engagement. On the contrary, planning is less strongly associated with low engagement and more with high engagement. The descriptive statistics are presented in Table 4. 


\section{Discussion}

The objectives of the present study were twofold: (1) to test a methodology to relate EEG data and data from a think-aloud protocol, and (2), to examine functional relations between psychophysiological and cognitive levels in the context of the performance of a complex cognitive task by a domain expert.

\subsection{Test of the methodology}

This objective was fully achieved. This case study has shown that it is possible to use psychophysiological measures within a context of high ecological value for studies in education. It indicates that it is possible to collect interpretable data across many levels of the human cognitive architecture concomitantly. More importantly, this methodology can be applied to authentic and significant contexts of learning and performance. In particular, the presence of speech and gesture, as it occurred naturally during the experiment, lead to interpretable data during $94 \%$ of the time. This result represents the performance of the equipment used, ABM's B-Alert $B$ system, which includes a relatively low-cost 9-electrode EEG net and decontamination/classification algorithm. It is reasonable to suggest that these encouraging performances can be enhanced and transposed into other systems, specifically dense-array EEG (128-256 electrodes), which affords source localization in addition to spectral analysis.

\subsection{Functional relations between psychophysiological and cognitive levels}

This objective was partially accomplished, in the sense that correlational information was obtained, but limitations in the methodology prevented the test of hypotheses regarding inter-level temporal causality using a sequential approach applied to discrete states (Gottman \& Roy, 1990).

The study reported has shown that distraction and drowsiness were not related to the type of cognitive activity or to the task component. However, relations were found with engagement and cognitive load, as discussed next.

\subsubsection{Type of cognitive activity (action regulation or task execution)}

As expected $(\mathrm{H} 1)$, action regulation was found to be more engaging than task execution. This corroborates the view that choice - especially in terms of task goals - during task performance improves positive affect towards the task. As hypothesized $(\mathrm{H} 2)$, cognitive load was not different between the two types of cognitive activity. This observation sheds new light on the idea that self- 
regulation is an additional burden during a learning task. It shows that selfregulation represents additional and recurring steps in performing a task, but cognitive load during these self-regulation episodes is not higher. Moreover, it has to be pointed out that the cost of self-regulation is minimal for a domain expert likely possessing schemas of the task and that this finding needs to be contrasted with the eventual study of novice participants for whom the present task may represent an opportunity to learn.

Hypotheses $\mathrm{H} 3$ and $\mathrm{H} 4$ were both rejected: distraction and drowsiness are both equally probable during action regulation and task execution. In line with the interpretation of $\mathrm{H} 2$, it is plausible that the schemas for the task were so automatized that regulation efforts were restricted to the monitoring of the task as going according to the routine.

\subsubsection{Type of task component (comprehension, reasoning, or planning)}

Contrary to the hypothesis $(\mathrm{H} 5)$, the participant was less engaged during reasoning and more engaged during planning. The pedagogical reasoning model stresses that the outcome of the process, the pedagogical planning, must be contingent on the student's needs and the educational context, as determined by adequate reasoning on the basis of required information through comprehension. Despite this sequential dependency, which has been shown in experts to involve recursion between comprehension and reasoning followed by planning (Mercier et al., 2010), the participant's engagement does not reflect the importance of the first steps for the outcomes of pedagogical reasoning but rather reflects the importance of the outcomes for the student's learning. Thus, in this case, engagement seems more related to the finality of the process rather than to the outcomes of the task's sub-processes. As hypothesized $(\mathrm{H} 6)$, planning is associated with a lower probability of high cognitive load. This psychophysiological evidence complements behavioral observations that planning is a fairly automatized activity for a domain expert. As predicted $(\mathrm{H} 7)$, distraction is equal among task components. Also as hypothesized (H8), drowsiness is equal among task components. As analyzed, the importance of distraction and drowsiness in the present performance context seems minimal. However, they can be viewed as critical variables in the study of cognitive load, especially in detecting episodes in which cognitive load is low, not as a result of low task demands, but instead because of off-task thoughts. 


\section{Conclusion}

This study used very recent EEG technology, which needs to be tested in a variety of contexts pertaining to human activity. Along these lines, the experiment was grounded in a cognitive model of a complex task, pedagogical reasoning, which has been characterized very rigorously using cognitive task analysis methodology and then tested empirically through a series of studies. In particular, a study in the work environment has shown that the model applies very well to the daily activities of novice and expert practitioners (Mercier, 2012b). This demonstration of the emerging possibility to integrate cognitive neuroscience methodology into ecologically-valid educational contexts echoes the call made by many (Howard-Jones, 2011).

The use of a single participant during this experiment makes the outcomes of this case study highly provisory. With respect to the hypotheses tested, the conclusions of this study need to be validated through replication studies, and this work would greatly benefit from the use of parametric samples. Moreover, the methodology tested appears to be sufficient to test expert-novice differences for example, bringing a new type of data into expertise research.

The limitation which has dramatically impaired expected innovations in multilevel process-oriented data analysis, in the context of a complex task, was the approximate temporal mapping between behavioral and psychophysiological data. The system-generated psychophysiological measures transform the 256-hz EEG signal to characterize the cognitive states in terms of second-by-second epochs. The trace thus produced is of an uncommon temporal grain size. Nevertheless, a better temporal resolution would be very beneficial to the specific context of application under study. In fact, an EEG signal measured every millisecond (a frequency of $1000 \mathrm{hz}$ ) is necessary to test causal hypotheses between levels in the cognitive architecture, in the tradition of sequential analysis. EEG source imaging has made tremendous progress in recent years to provide neurophysiological interpretations from scalp recordings (for a prototypical example, see Jrad \& Congedo, 2012). By showing the location of activation, source analysis brings additional explanatory power to EEG measurements and is now becoming the norm in the use of EEG in cognitive neuroscience. When no a priori assumptions can be made regarding the localization of activation (as is practically the case in the study of learning interactions), mathematical solutions can be used effectively to determine (1) when brain activation maps differ over time, thus segmenting microstates representing relatively stable brain activation patterns (lasting around $100 \mathrm{~ms}$ ), and (2) the localization of brain activation during those microstates. 
Microstates have explanatory power, represent functional "mind-states" during information-processing (Lehmann, Ozaki, \& Pal, 1987) and are increasingly viewed as the psychophysiological building blocks of cognition (Lehmann \& Michel, 2011). Research to date has identified four different classes of microstates, representing about $84 \%$ of the variance in the EEG signal. Research to date indicates that class $A$ refers to abstraction, class $B$ to concrete thought, class $C$ to decreased attention with decreased excitation, while the interpretation of class $D$ remains unclear. Their prevalence (mean duration, frequency of occurrence per second, percentage of occupied total analysis time) and sequence reflect different higher-order mental processes (Schlegel, Lehmann, Faber, Milz, \& Gianotti, 2012). For the time being, microstates may be among the most promising notions when using EEG in neuroeducation, as they appear to be suited for the discovery of psychophysiological signatures of cognitive functions responsible for learning (for example, social learning, metacognitive regulation in problem solving, insight in problem solving, implicit and explicit learning, etc.). Those events can be hypothesized to represent bottom-up or top-down processes and, as such, can be related to other levels in the cognitive architecture. Microstates can be related to cognitive and social events constituting authentic learning contexts. Since these are data-driven and not clock-generated by the EEG system, they can be implicated in intra-level and inter-level tests of temporal causality between processes.

In this study, the methodology was tested under possibly the most challenging circumstances to be found in educational contexts. Firstly, the participant was asked to write, to use a computer keyboard and mouse, and to talk aloud. Secondly, the analysis considered rapidly-switching discrete cognitive states as the behavioral layer. Such states, described in the pedagogical-reasoning model, typically last only about three seconds. This made the synchronization with the EEG system-generated one-second epochs difficult, as the cognitive states were very likely to shift during those seconds. In the context of spectral analysis, the ratios of different frequencies have to be measured over a certain period to be reliable, and it is difficult to imagine how low frequencies such as the delta band ( 0 to $3 \mathrm{hz}$ ) could be measured over shorter periods. This makes this approach better suited to analyses in which system-generated epochs are aggregated over longer task episodes, as can be seen from an accumulating body of studies. This approach has been used in the context of serious games for learning (Charland, Allaire-Duquette, Léger, \& Perret, 2012), IT-based learning simulations in the context of business management (Ortiz de Guinea, Titah, Léger, \& Michenau, 2012), military operations (Stevens et al., 2011) and in various work environments. It could be used productively with almost any 
population of learners in authentic learning situations, such as classroom lectures, autonomous learning tasks, and computer-based learning environments. Of special interest is the case of one-on-one human tutoring as well as computer tutoring situations, in complex domains as varied as remedial reading instruction (Mercier, 2012a), college physics (Mercier, 2013), and graduate-level statistics (Mercier \& Frederiksen, 2007). The moment-by-moment monitoring of engagement, workload, and alertness can provide valuable information to the tutor, and even to the tutee, so that appropriate countermeasures can be implemented to (re)establish a cognitive state conducive to learning. These variables can now be added to the growing list of student characteristics taken into account in tutoring.

\section{References}

Anderson, J. R. (2002). Spanning seven orders of magnitude: A challenge for cognitive modeling. Cognitive Science, 26(1), 85-112. https://doi.org/10.1016/s0364-0213(01)00062-3

Ansari, D., Coch, D., \& De Smedt, B. (2011). Connecting education and cognitive neuroscience: Where will the journey take us? Educational Philosophy and Theory, 43(1), 37-42. https://doi.org/10.1111/j.1469-5812.2010.00705.x

Azevedo, R., Moos, D. C., Johnson, A. M., \& Chauncey, A. D. (2010). Measuring cognitive and metacognitive regulatory processes during hypermedia learning: Issues and challenges. Educational Psychologist, 45, 4, 210-223. https://doi.org/10.1080/00461520.2010.515934

Berka, C., Levendowski, D. J., Cvetinovic, M. M., Petrovic, M. M., Davis, G., Lumicao, M. N., ..., \& Olmstead, R. (2004). Real-time analysis of EEG indexes of alertness, cognition and memory acquired with a wireless EEG headset. International Journal of Human-Computer Interaction, 17(2), 151170. https://doi.org/10.1207/s15327590ijhc1702 3

Berka, C, Davis, G., Johnson, R., Levendowski, D., Whitmoyer, M., Fatch, R., ..., \& Olmstead, R. (2007). EEG correlates of task engagement and mental workload in vigilance, learning and memory tasks. Aviation Space and Environmental Medicine, 78(5, suppl.), B231-B244. http://www.ingentaconnect.com/contentone/asma/asem/2007/00000078/A00 $\underline{105 \mathrm{~s} 1 / \mathrm{art} 00032}$ 
Charland, P., Allaire-Duquette, G., Léger, P.-M., \& Perret, J. (2012). Assessing cognitive state to investigate users' experience during game play: A neuroeducative perspective. Proceedings of the 5th International Conference on Computer Games Multimedia and Allied Technology, Denpasar, Indonesia: GSTF. https://doi.org/10.1037/e582722013-008

Chi, M., VanLehn, K., Litman, D., \& Jordan, P. (2011). An evaluation of pedagogical tutorial tactics for a natural language tutoring system: A reinforcement learning approach. International Journal of Artificial Intelligence in Education, 21, 83-113. https://doi.org/10.3233/JAl-2011-014

D'Mello, S., \& Graesser, A. (2012). Dynamics of affective states during complex learning. Learning and Instruction, 22, 145-57. https://doi.org/10.1016/j.learninstruc.2011.10.001

Geake, J. (2011). Position statement on motivations, methodologies, and practical implications of educational neuroscience research: fMRI studies of the neural correlates of creative intelligence. Educational Philosophy and Theory, 43(1), 43-47. https://doi.org/10.1111/j.1469-5812.2010.00706.x

Gottman, J. M., \& Roy, A. K. (1990). Sequential analysis: A guide for behavioral researchers. New York, NY : Cambridge University Press. https://doi.org/10.1017/cbo9780511529696

Grabner, R. H., \& Ansari, D. (2010). Promises and potential pitfalls of a cognitive neuroscience of mathematics learning. ZDM Mathematics Education, 42(6), 655-660. https://doi.org/10.1007/s11858-010-0283-4

Howard-Jones, P. A. (2011). A multiperspective approach to neuroeducational research. Educational Philosophy and Theory, 43(1), 24-30.

https://doi.org/10.1111/j.1469-5812.2010.00703.x

Jrad, S., \& Congedo, M. (2012). Identification of spatial and temporal features of EEG. Neurocomputing, 90, 66-71. https://doi.org/10.1016/j.neucom.2012.02.032

Kalyuga, S. (2009). Knowledge elaboration: a cognitive load perspective. Learning and Instruction, 19(5), 402-410.

https://doi.org/10.1016/j.learninstruc.2009.02.003

Lajoie, S. P. (2003). Transitions and trajectories for studies of expertise. Educational Researcher, 32(8), 21-25. https://doi.org/10.3102/0013189x032008021

Lee, K., \& Ng, S. F. (2011). Neuroscience and the teaching of mathematics. Educational Philosophy and Theory, 43(1), 81-86. https://doi.org/10.1111/j.1469-5812.2010.00711.x

Lehmann, D., \& Michel, C. M. (2011). EEG-defined functional microstates as basic building blocks of mental processes. Clinical Neurophysiology, 122(6), 10731074. https://doi.org/10.1016/i.clinph.2010.11.003 
Lehmann, D., Ozaki, H., \& Pal, I. (1987). EEG alpha map series: brain micro-states by space-oriented adaptive segmentation. Electroencephalography and Clinical Neurophysiology, 67(3), 271-288. https://doi.org/10.1016/00134694(87)90025-3

Matthews, G., Campbell, S. E., Falconer, S., Joyner, L.A., Huggins, J., Gilliland, K., ..., \& Warm, J. S. (2002). Fundamental dimensions of subjective state in performance settings: task engagement, distress and worry. Emotion, 2(4), 315-340. https://doi.org/10.1037//1528-3542.2.4.315

Mercier, J. (2013). The development of an interactive learning environment to foster pedagogical innovation through teachers' decision-making. In R. McBride \& M. Searson (Eds.), Proceedings of Society for Information Technology \& Teacher Education International Conference 2013 (pp. 3980-3985). Chesapeake, VA: Association for the Advancement of Computing in Education (AACE). https://www.editlib.org/p/48738/proceeding 48738.pdf

Mercier, J. (2012a). Fostering pedagogical innovation through teachers' decisionmaking: a cognitive point of view. Paper presented at the 2nd International Symposium on Integrating Research, Education, and Problem Solving (ICSIT 2012 Conference), Orlando, USA.

http://www.iiis.org/CDs2012/CD2012IMC/IREPS 2012/PapersPdf/IR429LZ.pdf

Mercier, J. (2012b). From laboratory to authentic contexts: two studies of pedagogical reasoning across four levels of expertise. World Journal of Education, 2(4), 2-19. https://doi.org/10.5430/wje.v2n4p2

Mercier, J., \& Frederiksen, C. (2007). Individual differences in graduate students' help-seeking process in using a computer coach in problem-based learning. Learning and Instruction, 17(2), 184-203. https://doi.org/10.1016/j.learninstruc.2007.01.013

Mercier, J., Girard, C., Brodeur, M., \& Laplante, L. (2010). Individual and collaborative learning in teaching: A trajectory to expertise in pedagogical reasoning. Hauppauge, NY: Nova Science Publishers.

Moscoso del Prado Martin, F. (2011). Causality, criticality, and reading words: Distinct sources of fractal scaling in behavioral sequences. Cognitive Science, 35(5), 785-837. https://doi.org/10.1111/j.1551-6709.2011.01184.x

Newell, A. (1990). Unified theories of cognition. Cambridge, MA: Harvard University Press.

Ortiz de Guinea, A., Titah, R., Léger, P.-M., \& Michenau, T. (2012). Neurophysiological correlates of information systems commonly used selfreported measures: $A$ multitrait multimethod study. $45^{\text {th }}$ Hawaii International Conference on System Sciences (HICSS-45), Maui, Hawaii. https://doi.org/10.1109/hicss.2012.448 
O'Brien, H., \& Toms, E. (2008). What is user engagement? A conceptual framework for defining user engagement with technology. Journal of the American Society for Information Science and Technology, 59(6), 938-955. https://doi.org/10.1002/asi.20801

Patel, V. L., Arocha, J. F., \& Zhang, J. (2005). Thinking and reasoning in medicine. In K. J. Holyoak and R. G. Morrison (Eds), The Cambridge handbook of thinking and reasoning (pp. 727-750). New York, NY: Cambridge University Press.

https://www.researchgate.net/publication/228872328 Thinking and reasonin $\mathrm{g}$ in medicine

Schlegel, F., Lehmann, D., Faber, P. L., Milz, P., \& Gianotti, L. R. R. (2012). EEG microstates during resting represent personality differences. Brain Topography, 25(1), 20-26. https://doi.org/10.1007/s10548-011-0189-7

Stevens, R. H., Galloway, T. L., Wang, P., \& Berka, C. (2011). Cognitive neurophysiologic synchronies: What can they contribute to the study of teamwork? Human Factors, 54(4), 489-502. https://doi.org/10.1177/0018720811427296

Sun, R. (2006). Prolegomena to integrating cognitive modeling and social simulation. In R. Sun (Ed.), Cognition and multi-agent interaction (pp. 3-26). New York, NY: Cambridge University Press.

https://doi.org/10.1017/cbo9780511610721.002

Sweller, J. (1988). Cognitive load during problem-solving: Effects on learning. Cognitive Science, 12(2), 257-285. https://doi.org/10.1207/s15516709cog1202 4

Tschan, F. (2002). Ideal cycles of communication (or cognitions) in triads, dyads, and individuals. Small Group Research, 33(6), 615-643.

https://doi.org/10.1177/1046496402238618

VanLehn, K. (2011). The relative effectiveness of human tutoring, intelligent tutoring systems, and other tutoring systems. Educational Psychologist, 46(4), 197221. https://doi.org/10.1080/00461520.2011.611369

Wickens, C. D., \& Hollands, J. G. (1999). Engineering psychology and human performance ( $3^{\text {rd }}$ ed.). Upper Saddle River, NJ: Prentice Hall.

Wood, H. \& Wood, D. (1999). Help seeking, learning and contingent tutoring. Computers \& Education, 33(2-3), 153-169. https://doi.org/10.1016/s0360$\underline{1315(99) 00030-5}$ 